\title{
PERDAS DE SOLO E NUTRIENTES NUM LATOSSOLO VERMELHO-AMARELO ÁCRICO TÍPICO, COM DIFERENTES SISTEMAS DE PREPARO E SOB CHUVA NATURAL ${ }^{(1)}$
}

\author{
Marcelo Henrique Siqueira Leite ${ }^{(2)}$, Eduardo Guimarães Couto ${ }^{(3)}$, \\ Ricardo Santos Silva Amorim( ${ }^{(4)}$, Eduardo Lenza da Costa ${ }^{(5)}$ \& Lucas \\ Maraschin $^{(6)}$
}

\begin{abstract}
RESUMO
O processo erosivo é a principal causa de degradação dos solos, trazendo, como consequência, prejuízos ao setor agrícola e ao meio ambiente, com reflexos econômicos e também sociais. Este trabalho foi realizado com o objetivo de avaliar as perdas de solo e nutrientes em diferentes sistemas de preparo num Latossolo Vermelho-Amarelo ácrico típico. Foram instaladas cinco parcelas experimentais contendo os seguintes tratamentos: preparo convencional e cultivo morro abaixo (CMA); preparo convencional e plantio em nível (CEN); preparo com uma grade aradora e uma niveladora e plantio em nível (CNiv); preparo com duas gradagens niveladoras, plantio em nível (NA) e cultivo mínimo em nível (CMN). As perdas de solo foram determinadas pelo método direto durante o ciclo da cultura de algodão, de dezembro de 2005 a junho de 2006. A cada coleta foram retiradas amostras de solo para quantificar as perdas dos nutrientes $\mathrm{N}, \mathrm{P}, \mathrm{K}$ e carbono orgânico (C-org) nos sedimentos. A diminuição no revolvimento do solo proporcionou menores perdas de sedimento, nutrientes e C-org, destacando o CMN como o mais eficiente.
\end{abstract}

\footnotetext{
(1) Parte da Dissetação de Mestrado do primeiro autor, apresentada à Faculdade de Agronomia e Medicina Veterinária, Universidade Federal de Mato Grosso - FAMEV. Executado com recursos da FAPEMAT. Recebido para publicação em abril de 2008 e aprovado em março de 2009.

${ }^{(2)}$ Mestre em Agricultura Tropical pela Universidade Federal de Mato Grosso - UFMT. Av. Fernando Corrêa S/N, CEP 78060-900 Cuiabá (MT). E-mail: sleitebrum@gmail.com

(3) Professor Associado do Departamento de Solos e Engenharia Rural da Faculdade de Agronomia e Medicina Veterinária, Universidade Federal de Mato Grosso - FAMEV/UFMT. Av. Fernando Corrêa S/N, CEP 78060-900 Cuiabá (MT). E-mail: couto@ufmt.br

(4) Professor Adjunto do Departamento de Solos e Engenharia Rural da Faculdade de Agronomia e Medicina Veterinária da FAMEV/UFMT. E-mail: rsamorim@ufmt.br

(5) Graduando em Agronomia da UFMT. E-mail: eduardolenzadacosta@hotmail.com

(6) Mestrando em Agricultura Tropical da FAMEV/UFMT. E-mail: agrosucesso@yahoo.com.br
} 


\begin{abstract}
As perdas de N, $\mathrm{P}, \mathrm{K}$ e C-org nos sedimentos apresentaram tendências semelhantes às das perdas de solo, e $\mathrm{N}, \mathrm{P}$ e $\mathrm{K}$ variaram conforme as adubações utilizadas. $\mathrm{O}$ C-org foi encontrado em maior quantidade no sedimento. A taxa de infiltração básica (TIB) expressou diferença entre os tratamentos na seguinte ordem em valores crescentes: $\mathrm{CMA}<\mathrm{CEN} \cong \mathrm{CNiv} \cong \mathrm{NA}<\mathrm{CMN}$, demonstrando que os sistemas de preparo que minimizam a movimentação do solo e incrementam C-org aumentam a TIB e diminuem o processo erosivo.
\end{abstract}

Termos de indexação: erosão, perda de C orgânico, taxa de infiltração básica.

\title{
SUMMARY: SOIL AND NUTRIENT LOSSES UNDER DIFFERENT TILLAGE SYSTEMS IN A CLAYEY OXISOL UNDER NATURAL RAINFALL
}

\begin{abstract}
Erosion is the main cause of soil degradation, and it leads to adverse effects to agriculture and environment, with social and economic implications. The objective of this study was to evaluate soil and nutrient losses in different soil tillage systems in a typic Acric Red-Yellow Latosol (Oxisol). On five plots with the following soil tillage treatments were evaluated: conventional tillage and down-slope tillage (CMA); conventional tillage and contour seeding $(C E N)$; tillage with one passage of heavy disk harrow and one passage of leveling harrow and contour seeding (CNiv); tillage with two passages of leveling harrow and contour seeding (NA) and no tillage and contour seeding (CMN). The soil losses were determined by the direct method during the cotton crop cycle, from December 2005 to June 2006. Along each runoff sampling, soil samples were withdrawn to quantify the losses of $N, P, K$ and organic carbon (C-org) in the sediments. Decreasing soil tillage lessened the losses of sediments, nutrients and organic carbon, indicating that the CMN treatment was the most efficient. The trends for $N, P$, $K$ and $C$-org losses in the sediments were similar to the soil losses. N, Pand K varied according to the fertilizers used. The constituent with the highest concentration in the sediment was $C$ in organic compounds. The basic infiltration rate differed among the treatments in the following order: $C M A<C E N \cong C N i v \cong N A<C M N$, indicating that tillage systems that reduced soil revolving and increased organic $C$, increased the basic infiltration rate and decreased soil erosion.
\end{abstract}

Index terms: erosion, organic carbon loss, basic infiltration rate.

\section{INTRODUÇÃO}

De acordo com estimativas recentes, feitas por Hernani et al. (2002), as perdas anuais de solo em áreas ocupadas por lavouras e pastagens, no Brasil, são da ordem de 822,7 milhões de toneladas. Esses autores estimaram que tais valores estariam associados a uma perda total, na propriedade rural, de US $\$ 2,93$ bilhões por ano. Os autores relatam que a erosão acarreta ao Brasil um prejuízo total de aproximadamente US $\$ 4,24$ bilhões por ano.

No Estado do Paraná, pesquisas evidenciaram perdas de solo de 15 a $20 \mathrm{tha}^{-1} \mathrm{ano}^{-1}$ em áreas intensivamente mecanizadas (Paraná, 1989). No Estado de São Paulo, a perda anual devida à erosão é de aproximadamente 194 milhões de toneladas de terras férteis, e 48,5 milhões de toneladas em forma de sedimentos, causando assoreamento e poluição (Tapia-Vargas et al., 2001). Segundo Bertolini et al. (1993), são perdidos em torno de $10 \mathrm{~kg}$ de solo para cada quilo de soja e $12 \mathrm{~kg}$ de solo para cada quilo de algodão produzidos no Estado de São Paulo, pelo uso e manejo inadequados do solo. Bertol et al. (2007) estimaram as perdas financeiras causadas pela erosão no Planalto Catarinense e demonstraram que o valor monetário da perda anual por hectare de K, expresso na forma de $\mathrm{KCl}$, por erosão hídrica, foi equivalente a 2,6 vezes aquele representado pelo somatório das perdas de P na forma de superfosfato triplo e de Ca e Mg na forma de calcário, na média dos sistemas de manejo do solo estudados.

A cobertura do solo proporcionada pelos resíduos culturais deixados na superfície tem ação direta e efetiva na redução da erosão hídrica, em virtude da dissipação de energia cinética das gotas da chuva, diminuindo a desagregação das partículas de solo e o selamento superficial e aumentando a infiltração de água no solo. Ela atua ainda na redução da velocidade do escoamento superficial e, consequentemente, da capacidade erosiva da enxurrada. A percentagem de cobertura do solo proporcionada pelas restevas das culturas é fator fundamental na redução das perdas 
de solo por erosão hídrica (Sloneker \& Moldenhauer, 1977), obtendo-se boa eficácia já com $30 \%$ de cobertura (Lopes et al., 1987). No entanto, a persistência dessa proteção ao solo depende do grau de incorporação dos resíduos culturais, bem como do método de preparo e, ou, da semeadura. O tipo de implemento utilizado e a intensidade do preparo modificam a quantidade de resíduos culturais remanescentes na superfície e a cobertura do solo (Schick et al., 2000), podendo esses resíduos ser incorporados total e parcialmente, no caso do preparo convencional e do cultivo mínimo, respectivamente, ou mantidos praticamente todo na superfície no caso da semeadura direta (Bertol et al., 1997).

Os sistemas convencionais aumentam o volume de poros dentro da camada preparada, e a permeabilidade e o armazenamento de ar facilitam o crescimento das raízes das plantas nessa camada, em relação à semeadura direta e ao campo nativo (Bertol et al., 2000). No entanto, abaixo dessa camada, contrariamente ao que ocorre na semeadura direta e no campo nativo, ocorre redução dessas propriedades apresentando comportamento inverso da superfície (Bertol et al., 2000). Além disso, os aspectos positivos dos preparos convencionais são perdidos, quando o solo, descoberto pelo efeito do preparo, é submetido ao impacto direto das gotas da chuva, favorecendo o desprendimento das partículas de solo e o selamento superficial, consequentemente diminuindo a taxa de infiltração e aumentando o escoamento superficial, o que favorece, a erosão hídrica (Bertol et al., 1997).

As perdas de água, de modo geral, têm sido variadas e bem menos influenciadas pela cobertura superficial morta do que as perdas de solo. $\mathrm{Na}$ literatura, os resultados de perda de água não têm apresentado certa consistência, sendo observada perda de água maior na semeadura direta (Vieira et al., 1978), bem como no preparo reduzido e convencional (Nunes et al., 1987), ou mesmo semelhante entre os diferentes métodos de preparo do solo, dependendo do regime de chuva, do tipo de solo, da topografia e sequência/rotação cultural utilizada no sistema global de manejo do solo da propriedade.

A água da enxurrada transporta nutrientes solúveis e adsorvidos aos sedimentos transportados. A concentração de nutrientes no escoamento superficial da erosão hídrica varia principalmente com sua concentração no solo, que é influenciada pelo tipo de solo, pelas adubações e pelo tipo de manejo empregado. A quantidade total do nutriente transportado pela erosão hídrica, no entanto, depende da sua concentração no material erodido e do volume total desse material perdido pela erosão (Seganfredo et al., 1997).

Estudos relativos à eficácia de sistemas conservacionistas de manejo do solo no controle de perdas de nutrientes indicam que o total de nutrientes perdidos por erosão hídrica decresce quando tais sistemas são utilizados, em relação aos convencionais (Seganfredo et al., 1997).
No Estado de Mato Grosso, há escassez de informações para avaliar os impactos ambientais relacionados ao processo erosivo. Estudos da literatura são frequentemente baseados na extrapolação dos resultados de pesquisas de outros Estados. Dessa forma, objetivou-se, neste trabalho, avaliar as perdas de solo e nutrientes em diferentes sistemas de preparo num Latossolo Vermelho-Amarelo àcrico típico, sob chuva natural, em lavoura comercial de algodão de Mato Grosso.

\section{MATERIAL E MÉTODOS}

O experimento foi realizado entre novembro de 2005 e agosto de 2006, localizado na Fazenda Mourão I, situada entre $15^{\circ} 26^{\prime} 40$ " de latitude sul e $54^{\circ} 55^{\prime} 12$ " de longitude oeste, próximo ao município de Campo-Verde-MT. O solo da área é um Latossolo Vermelho-Amarelo ácrico típico, segundo o sistema de classificação da Embrapa (2006), de textura argilosa e declividade média de $0,025 \mathrm{~m} \mathrm{~m}^{-1}$.

A área vem sendo conduzida há cinco anos sob o sistema de cultivo mínimo, com a mobilização do solo de destruição da soqueira do algodão e a gradagem superficial (grade niveladora a aproximadamente $5 \mathrm{~cm}$ ), ou correntão para incorporação da semente de milheto. A última calagem na área foi realizada um ano antes do início da adoção do sistema de cultivo mínimo. O milheto é utilizado como cobertura vegetal para a formação de palhada, sendo as sementes distribuídas a lanço e, em seguida, incorporadas com grade leve (Quadro 1).

As adubações referentes à safra 2005/2006 foram realizadas em três momentos distintos: a de base (NPK), a lanço, no dia 22 de outubro; a primeira adubação de cobertura (N), em dezembro, 15 dias após emergência (DAE), e a segunda 50 DAE (Quadro 2).

O plantio do algodão, em todos os tratamentos, foi realizado com semeadora de plantio direto no dia 9 de dezembro de 2005, com espaçamento entre linhas de $90 \mathrm{~cm}$, densidade de 10 sementes por metro linear de sulco e profundidade de aproximadamente $3 \mathrm{~cm}$. A colheita foi realizada no dia 26 de junho de 2006 para cada tratamento.

A unidade experimental de erosão hídrica constituiu-se de uma parcela com $22,1 \mathrm{~m}$ de comprimento e 3,5 m de largura, delimitada em sua extremidade superior e nas laterais por chapas galvanizadas, cravadas $0,10 \mathrm{~m}$ no solo, providas de um sistema coletor de enxurrada na sua extremidade inferior. Esse coletor era uma calha coletora conectada por meio de um tubo de PVC a uma estrutura de coleta posicionada na extremidade inferior da área experimental, consistindo de uma caixa retangular, construída de chapa galvanizada, com um sistema de filtragem (manta geotêxtil). Esta caixa tem uma saída 
Quadro 1. Histórico da área, safras, culturas, adubações, implementos e épocas dos manejos

\begin{tabular}{|c|c|c|c|c|c|c|c|c|c|}
\hline \multirow{2}{*}{ Safra } & \multirow{2}{*}{ Cultura } & \multirow{2}{*}{ Época } & \multirow{2}{*}{ Implemento } & \multicolumn{6}{|c|}{ Adubação } \\
\hline & & & & MAP & $\mathrm{KCl}$ & Ureia & SA & SS & Produbor \\
\hline & & & & & & $-\mathrm{kg}$ & $a^{-1}$ & & - \\
\hline \multirow[t]{3}{*}{$2005 / 2006$} & Milheto & Outubro & Correntão (incorporar semente) & 100 & 80 & & & 130 & 20 \\
\hline & Algodão & Dezembro & & & 140 & & 180 & & \\
\hline & & Janeiro & & & & 150 & & & \\
\hline
\end{tabular}

MAP: fosfato monoamônico; KCl: cloreto de potássio; SA: sulfato de amônio; SS: superfosfato simples; Produbor: boro.

Quadro 2. Análise da estabilidade dos agregados nos diferentes preparos de solo

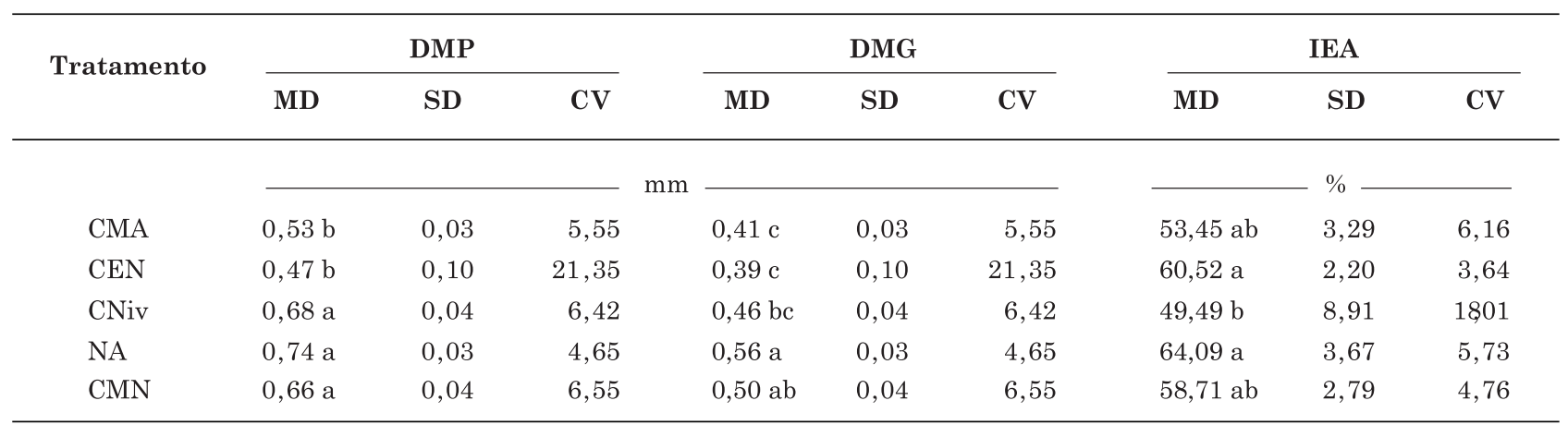

CMA: preparo convencional morro abaixo; CEN: preparo convencional em nível; CNiv: preparo convencional com uma gradagem niveladora; NA: preparo com duas gradagens niveladoras; CMN: cultivo mínimo em nível; DMP: diâmetro médio ponderado; DMG: diâmetro médio geométrico; IEA: índice de estabilidade dos agregados, MD: média; SD: desvio-padrão; CV: coeficiente de variação. Médias seguidas da mesma letra na coluna não diferem entre si, a $5 \%$, pelo teste de Tukey.

composta por um divisor tipo "Geib", provido de nove aberturas, e a abertura central é conectada a um tambor que armazenava o volume de escoamento que passou pela fração de 1/9 da calha Geib.

Cada parcela recebeu tratamento diferenciado quanto ao tipo de preparo do solo, todas cultivadas com algodão (Gossypium hirsutum) e com os seguintes tratamentos: preparo convencional (uma grade aradora e duas niveladoras) e cultivo morro abaixo (CMA); preparo convencional e plantio em nível (CEN); preparo com uma grade aradora e uma niveladora $\mathrm{e}$ plantio em nível (CNiv); preparo com duas gradagens niveladoras e plantio em nível (NA); cultivo mínimo na palha em nível (CMN). Este ultimo tratamento foi considerado cultivo mínimo, já que o solo sofreu gradagem leve para a incorporação das sementes de milheto.

A precipitação pluvial total que incidiu sobre a área experimental foi medida diariamente por pluviômetros instalados na área das parcelas, permitindo avaliar a lâmina de precipitação incidente cada uma.

A cada mês foi calculado o coeficiente de chuva (Rc), utilizando-se os valores pluviométricos médios mensais. O coeficiente de chuva foi determinado pela equação (1), proposto por Bertotoni \& Lombardi Neto (1990):

$$
R c=\frac{(P m)^{2}}{P a}
$$

em que $R c$ : coeficiente de chuva para o período entre coletas; $P m$ : precipitação pluvial média no período entre coletas (mm); Pa: precipitação pluvial média anual $(\mathrm{mm})$.

A determinação da erosividade da chuva a partir de dados pluviométricos foi realizada com base no ajuste do método proposto por Bertoni \& Lombardi Neto (1990), que estima o índice $\mathrm{EI}_{30}$ por meio do coeficiente de chuva, utilizando a equação (2):

$$
E I=56,115\left(R_{c}\right) 0,9504
$$

em que $E I$ : índice de erosividade $\left(\mathrm{EI}_{30}\right)$ médio do período (MJ mm ha ${ }^{-1} \mathrm{~h}^{-1}$ ); $R_{c}$ : coeficiente de chuva.

Os valores dos parâmetros 56,115 e 0,9504 da equação (2) foram ajustados por Morais et al. (1991) para estações de Cuiabá, localizadas a $130 \mathrm{~km}$ da área de experimento, sendo os valores mais próximos até o momento das respectivas estimativas. 
A taxa de infiltração foi feita com o simulador de chuvas portátil, sendo realizadas duas repetições por parcela. Os testes foram feitos cravando-se um anel no solo até aproximadamente $20 \mathrm{~cm}$, no qual se aplicou água numa intensidade de precipitação pluvial média de $119 \mathrm{~mm} \mathrm{~h}^{-1}$, por meio de um simulador de chuvas portátil. Este anel continha um furo que ficava rente à superfície do solo onde foi conectada uma mangueira para coleta do escoamento.

A coleta e determinação do volume da água escoada, em cada teste, foram feitas a cada intervalo de $5 \mathrm{~min}$, até que o volume escoado superficialmente se tornasse quase constante.

De posse dos resultados, foi realizado ajuste de modelo para cada tratamento, utilizando-se o modelo de Kostiakov (Pruski, 1997). Em seguida, fez-se o teste de identidade de modelos para testá-los estatisticamente, ajustados para os diferentes tratamentos a $10 \%$.

O escoamento superficial, juntamente com os sedimentos transportados das parcelas experimentais, ocorreu por meio de tubos de PVC (100 mm) para uma estrutura de coleta posicionada na extremidade de menor cota da área experimental. Nessa estrutura, os sedimentos transportados foram retidos no filtro (manta geotêxtil) previamente pesado, que possibilitou a coleta das partículas de solo mais grosseiras transportadas (Pereira, 1999; Silva et al., 2005). Tendo em vista que a manta não retinha todos os diâmetros de partículas de solo em suspensão no escoamento superficial, a cada coleta de dados o volume de água no tambor de armazenamento era homogeneizado e retirada uma alíquota para determinação da quantidade de solo em suspensão que passou pelo filtro. Esta massa era somada à massa de solo retida no filtro para totalizar a perda de solo. Os dados de perda de solo obtidos no campo foram ajustados para o declive médio da parcela padrão $\left(0,09 \mathrm{~m} \mathrm{~m}^{-1}\right)$, utilizando a equação recomendada por Wischmeier \& Smith (1978).

A cada determinação das perdas de solo nas parcelas foram retiradas amostras para quantificação de $\mathrm{N}$, $\mathrm{P}, \mathrm{K}$ e C orgânico (C-org) nos sedimentos. O P e K nos sedimentos foram extraídos com Mehlich- $1\left(\mathrm{H}_{2} \mathrm{SO}_{4}\right.$ 0,0125 $\mathrm{mol} \mathrm{L}^{-1}+\mathrm{HCl} 0,05 \mathrm{~mol} \mathrm{~L}^{-1}$ ), sendo o P determinado por espectrofotometria e o K pelo método de fotometria de chama, segundo método da Embrapa (1997).

$\mathrm{O} \mathrm{N}$ no solo foi determinado segundo método semimicro-Kjeldahl, e o C-org foi determinado pelo método Walkley \& Black modificado (Jackson, 1958), baseado na oxidação da matéria orgânica pelo dicromato de $\mathrm{K}$, sendo a difenilamina utilizada como indicador.

Cerca de 60 dias após a semeadura, foram retiradas amostras de solo para a análise de agregados por via úmida na profundidade de 0-20 cm. Essas amostras foram secas ao ar, após serem cuidadosamente destorroadas à mão, quebrando os agregados maiores. Em seguida, foram passadas em peneira com abertura de malha de $4 \mathrm{~mm}$ e retidas na de $2 \mathrm{~mm}$, homogeneizadas e pesados $50 \mathrm{~g}$ em três repetições. Uma das amostras foi colocada em lata de alumínio de peso conhecido, levada em estufa a $105^{\circ} \mathrm{C}$ por uma noite. Após esfriar, foi pesada para posterior utilização no cálculo do teor de agregados.

A determinação da estabilidade dos agregados em água foi feita utilizando-se o aparelho de oscilação vertical. Para cada amostra de campo, foram feitas quatro repetições. Os valores obtidos foram usados para cálculo do diâmetro médio ponderado dos agregados (DMP), diâmetro médio geométrico dos agregados (DMG) e índice de estabilidade dos agregados (IEA) (Castro Filho et al., 1998):

$$
D M P=\Sigma\left(C_{m m} \times P\right)
$$

em que $D M P$ : diâmetro médio ponderado; $C_{m m}$ : centro das classes (mm); $P$ : proporção do peso de cada fração de agregados em relação ao total da amostra.

$$
I E A=\frac{(M S-w p 0,25-\text { areia })}{(M S-\text { areia })} \times 100
$$

em que $M S$ : massa da amostra seca (g); $w p 0,25$ : massa dos agregados da classe $<0,25(\mathrm{~g})$.

$$
\begin{gathered}
D M G=10^{\mathrm{X}} \\
x=\left[\sum(n \log \mathrm{Cmm}) / \sum n\right]
\end{gathered}
$$

em que $n=$ percentagem de agregados nas diversas classes das peneiras.

A análise estatística constou de um ajuste de modelos para descrever as tendências das perdas de solo, nutrientes e C-org em sedimento e a taxa de infiltração de água no solo ao longo do tempo para cada tratamento. Após definir os modelos, realizouse o teste para identificá-los com o intuito de verificar estatisticamente a diferença entre os tratamentos, das variáveis, adotando-se a probabilidade de $10 \%$.

Quanto aos atributos físicos, índice de estabilidade dos agregados, diâmetro médio geométrico e ponderado, foram realizadas uma análise descritiva dos dados (média, desvio-padrão, coeficiente de variação), em seguida uma análise de variância (ANOVA) e teste de comparação de médias (Tukey), ambos a $5 \%$.

\section{RESULTADOS E DISCUSSÃO}

Os sistemas de preparo diferiram entre si estatisticamente quanto aos valores da taxa de infiltração básica (Figura 1), permitindo separá-la em três grupos. O primeiro foi responsável pela mais baixa taxa de infiltração básica (TIB), observada no tratamento CMA (preparo convencional morro abaixo), com valor 
de $10,50 \mathrm{~mm} \mathrm{~h}^{-1}$. O segundo foi composto pelos tratamentos CEN, CNiv e NA com TIB variando de 20,0 a $23,6 \mathrm{~mm} \mathrm{~h}^{-1}$, que não apresentaram diferenças significativas entre si. Por fim, o terceiro foi o CMN, que apresentou maior TIB $\left(43,5 \mathrm{~mm} \mathrm{~h}^{-1}\right)$, diferindo dos demais tratamentos, o que pode ser explicado pela palhada que permanece na superfície, dissipando a energia cinética da chuva, reduzindo o selamento superficial e, consequentemente, melhorando a capacidade de infiltração de água do solo. De acordo com Cogo et al. (1984) e Bertol et al. (1997), o cultivo mínimo dificulta mecanicamente o escoamento, além de melhorar a estruturação do solo, facilitando, dessa forma, a infiltração da água no solo.

$\mathrm{Na}$ análise de agregados, pode-se observar que, quanto mais intenso o preparo do solo (CMA e CEN), menores o diâmetro médio ponderado e o diâmetro médio geométrico (Quadro 2). Essas práticas são as principais responsáveis pela quebra dos agregados e exposição do solo, causando degradação de sua estrutura, o que consequentemente proporcionou as maiores perdas de solo neste estudo.

Os maiores valores de diâmetro médio ponderado e geométrico foram observados nos tratamentos NA, CNiv e CMN, sendo este significativamente superior aos dos tratamentos CMA e CEN, principalmente para o diâmetro médio ponderado, evidenciando o efeito da desestruturação que este tipo de preparo proporciona ao solo, o que afetará a quantidade de sedimentos

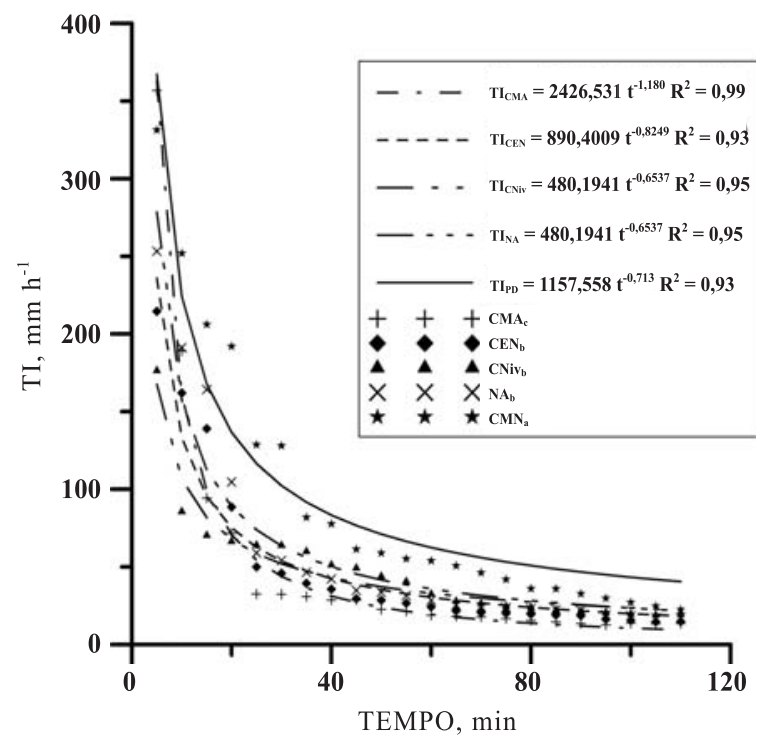

Figura 1. Taxa de infiltração de água (TI) nos diferentes preparos de solo. CMA: preparo convencional morro abaixo; CEN: preparo convencional em nível; Cniv: preparo convencional com uma gradagem niveladora; NA: preparo com duas gradagens niveladoras; CMN: cultivo mínimo em nível. Letras iguais não diferem estatisticamente a $10 \%$ pelo teste de identidade de modelos ajustados aos dados de taxa de infiltração. carreados pelo escoamento superficial, bem como o processo de formação do selamento superficial do solo. O índice de estabilidade dos agregados apresentou certa incoerência nos resultados, uma vez que no preparo convencional (CEN) os valores foram mais baixos que no conservacionista $(\mathrm{CMN})$, provavelmente em função do curto intervalo de tempo (60 dias) entre o preparo do solo e a coleta para análise de agregados.

A variação na estabilidade dos agregados em diferentes sistemas de manejo pode ser atribuída às diferenças no teor de C-org do solo, demonstrando a importância da matéria orgânica como agente de agregação das partículas do solo. Desta forma, práticas que causam a degradação da estrutura do solo pelo impacto da gota de chuva, pela diminuição do teor de matéria orgânica e pelo intenso preparo do solo, como nos tratamentos CMA e CEN, aumentam as proporções dos agregados de menor tamanho, favorecendo as perdas dos sedimentos.

Forças desagregantes favorecem o aumento das perdas. Estas forças podem ser advindas da abrasão em diferentes preparos e implementos, do impacto das gotas de chuva, bem como do cisalhamento pelo fluxo de água, e, ou, pela entrada de água nos agregados. Esses fatores são, em grande parte, alterados pelos sistemas de manejo adotados não só pelo efeito direto do revolvimento mecânico ocasionado durante o preparo do solo, que favorece sua degradação, principalmente por ação da erosão hídrica, mas também pelas modificações no ambiente edáfico (Lima et al., 2003).

Na figura 2a,b estão apresentadas as perdas de solo e os percentuais das perdas de cada coleta em relação à perda total, respectivamente. Observa-se (Figura 2a) que as perdas de solo são mais elevadas nas primeiras coletas, ou seja, antes do estabelecimento da cultura, período mais crítico pela maior erosividade. Apesar da erosividade da chuva ser maior na primeira coleta, a perda de solo não foi maior pela pouca frequência de chuva, pois no início do período de coleta de dados as chuvas foram mais espaçadas, pelo aumento instantâneo da capacidade de infiltração do solo na camada preparada, principalmente nas parcelas que sofreram a mobilização do solo.

Verifica-se (Figura 2b), que até a terceira coleta de dados ocorreu cerca de $45 \%$ das perdas de solo no tratamento CMA, sendo verificado que, neste tratamento, as perdas de solos foram maiores em todas as coletas. Esses resultados são coerentes com aqueles obtidos por Eltz et al. (1977), Amado et al. (1989), Carvalho et al. (1990) e Seganfredo et al. (1997), que observaram grande redução nas perdas de solo com a presença da cobertura vegetal.

No preparo CEN, pode-se observar que as quantidades de solo perdidas ao longo das coletas em relação ao total, expressas em percentuais, apresentaram também comportamento semelhante ao tratamento CMA, ou seja, maiores perdas no início do 

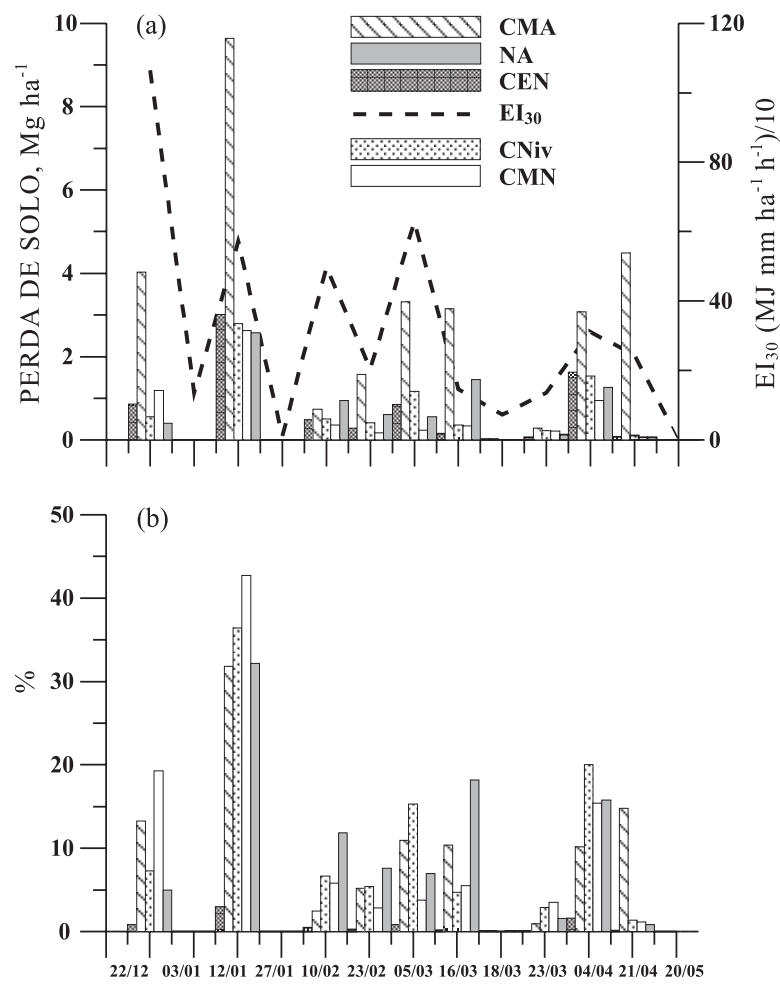

COLETA

Figura 2. Índice de erosividade de chuva $\left(\mathrm{EI}_{30}\right)$ e perdas de solo (a), percentuais das perdas em cada coleta (b); no período de dezembro de 2005 a junho de 2006 em diferentes preparos de solo na Fazenda Mourão I. CMA: convencional morro abaixo; NA: duas gradagens niveladoras; $\mathrm{CEN}$ : convencional em nível; CNiv: convencional com uma gradagem niveladora; $\mathrm{CMN}$ : cultivo mínimo em nível.

crescimento da cultura, ocorrendo até a terceira coleta $52 \%$ das perdas de solo (Figura 2b). Já os tratamentos CNiv e NA apresentaram perdas muito próximas em termos quantitativos e de tendência.

As perdas de solo no tratamento CMN foram relativamente altas no início das coletas quando comparada aos demais tratamentos estudados (Figura 2a), devido ao fato de no sistema de preparo convencional do solo ter havido inicialmente aumento da porosidade do solo, favorecendo a infiltração da água e, consequentemente, a redução da ação erosiva do escoamento superficial, o que não se verifica no CMN, uma vez que neste tratamento não houve preparo do solo.

Vale ressaltar que esses dados são referentes ao primeiro ano em que estas práticas de manejo do solo foram adotadas, sendo necessário um período maior para que o cultivo mínimo (CMN) se estabeleça. Quanto ao comportamento das perdas em percentuais no CMN (Figura 2b), até a terceira coleta ocorreram $62 \%$ de perdas de solo, justificados pelos mesmos motivos relacionados aos demais tratamentos.
A eficiência da cobertura vegetal em reduzir as perdas de solo pode ser atribuída, principalmente, à proteção da superfície do solo proporcionada pelas copas das plantas, impedindo o impacto direto das gotas de chuva sobre a superfície, diminuindo a desagregação do solo e resultando em baixa concentração de sedimentos no escoamento superficial. Além disso, na presença de plantas, grandes quantidades de água são transpiradas, reduzindo a umidade do solo, aumentando com isso a taxa de infiltração de água no solo e reduzindo o volume de escoamento superficial; reduzindo a tendência ao encrostamento do solo; e aumento da rugosidade superficial, reduzindo a velocidade do escoamento superficial e, consequentemente, sua erodibilidade (Dedecek et al., 1986; Seganfredo et al., 1997).

As perdas de $\mathrm{N}$ nos sedimentos, no tratamento CMA, durante o ciclo da cultura do algodoeiro (Figura 3a), acompanharam as perdas de solo ao longo do tempo e, de certa forma, as adubações minerais de cobertura, conforme pode ser observado no histórico de área (Quadro 1): até a terceira coleta, $33 \%$ do N foi perdido nos sedimentos (Figura 3b). Isto pode ser atribuído à menor cobertura vegetal nos estádios iniciais de desenvolvimento e períodos mais erosivos, conforme já discutido. Preparos convencionais como o CMA mostram-se mais suscetíveis às perdas de $\mathrm{N}$ que preparos conservacionistas, em função do revolvimento constante do solo, facilitando a decomposição dos resíduos vegetais e a liberação de $\mathrm{N}$.

Quanto às perdas de N no preparo CEN, pode-se observar que quantidades perdidas ao longo das coletas em relação ao total, expressas em percentuais, apresentaram também comportamento semelhante ao tratamento CMA (Figura 3b), ou seja, maiores perdas no início do desenvolvimento da cultura, ocorrendo até a terceira coleta $48 \%$ de perdas de N.

Ao analisar conjuntamente as perdas de $\mathrm{N}$ nos tratamentos CNiv e NA (Figura 3a), observam-se maiores perdas do elemento no preparo NA em comparação ao CNiv, devido à incorporação parcial dos resíduos vegetais no solo pelos respectivos preparos. No preparo NA, os resíduos foram incorporados mais superficialmente, o que favoreceu a decomposição dos resíduos e a mineralização do nutriente, disponibilizando-o na superfície do solo e próximo dela para o transporte pelo escoamento superficial (Guadagnin et al., 2005).

Preparos conservacionistas como o CMN (Figura 3a) mostraram-se menos suscetíveis às perdas de $\mathrm{N}$ do que os preparos convencionais, o que se deve à mínima mobilização do solo neste tratamento, dificultando a decomposição dos resíduos vegetais e a liberação de $\mathrm{N}$ em relação aos preparos convencionais.

Analisando as perdas de $\mathrm{P}$, ao longo do ciclo do algodoeiro (Figura 4a), pode-se observar que foi o nutriente perdido em menor quantidade, devido às suas baixas concentrações nos sedimentos erodidos e na 

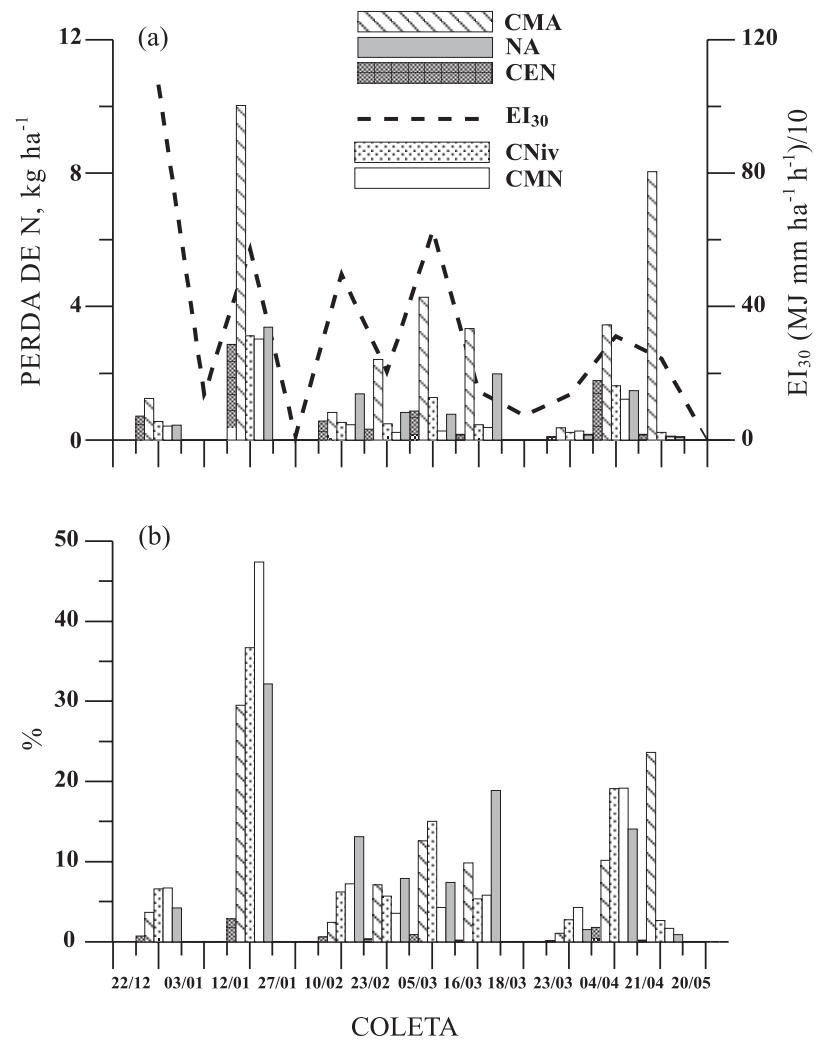

Figura 3. Índice de erosividade de chuva $\left(\mathrm{EI}_{30}\right)$ e perdas de nitrogênio (a); percentuais das perdas em cada coleta (b); no período de dezembro de 2005 a junho de 2006 em diferentes preparos de solo na Fazenda Mourão I. CMA: convencional morro abaixo; NA: duas gradagens niveladoras; CEN: convencional em nível; CNiv: convencional com uma gradagem niveladora; $\mathrm{CMN}$ : cultivo mínimo em nível.

camada de 0-20 cm. Resultados semelhantes foram obtidos em outros estudos (Eltz et al.,1989; Schick et al., 2000; Bertol et al., 2004).

Ao observar a tendência das perdas de $\mathrm{P}$ em termos percentuais em diferentes coletas (Figura 4b) no preparo CMA, verifica-se um resultado atípico: $45 \%$ de perda deste elemento na penúltima coleta (21/04/ 2006), possivelmente pela concentração do elemento nesta coleta, cerca de dez vezes maior que a média das coletas anteriores, fato que pode ser explicado pelas adubações efetuadas no solo e pelos resíduos vegetais das culturas anteriores.

As perdas de $\mathrm{K}$ no preparo CMA durante o ciclo (Figura 5a) foram similares às perdas de solo. As maiores perdas de $\mathrm{K}$ ocorreram no início do ciclo da cultura. Até a terceira coleta de dados, houve perda de $62 \%$ deste elemento (Figura 5b), atribuindo-se a este fato a menor cobertura vegetal nos estádios iniciais de crescimento da planta e aos períodos de chuvas mais erosivas, conforme já abordado anteriormente.
As perdas de $\mathrm{C}$ nos sedimentos (Figura 6a) tiveram comportamento semelhante ao da maioria dos nutrientes discutidos até o momento, tendo como principal diferença os valores muito mais elevados, quando comparados aos demais nutrientes. Da primeira à terceira coleta, foram perdidos aproximadamente $50 \%$ de C-org (Figura 2b) no preparo CMA, o que corresponde a $300 \mathrm{~kg} \mathrm{ha}^{-1}$ do elemento, enfatizando a importância de práticas conservacionistas que reduzem a ação erosiva da chuva, mantendo esta fração orgânica no solo, uma vez que ela é importante na manutenção da sua estrutura, retenção de umidade e CTC.

O C-org possui alta afinidade com a fração argila e os nutrientes, ocorrendo dessa forma erosão com caráter seletivo e também pelo fato de a matéria orgânica e a fração coloidal serem os primeiros constituintes removidos pela erosão hídrica, tendo em vista sua baixa densidade (Seganfredo et al., 1997).

De forma semelhante aos tratamentos discutidos anteriormente e também justificados pelos mesmos
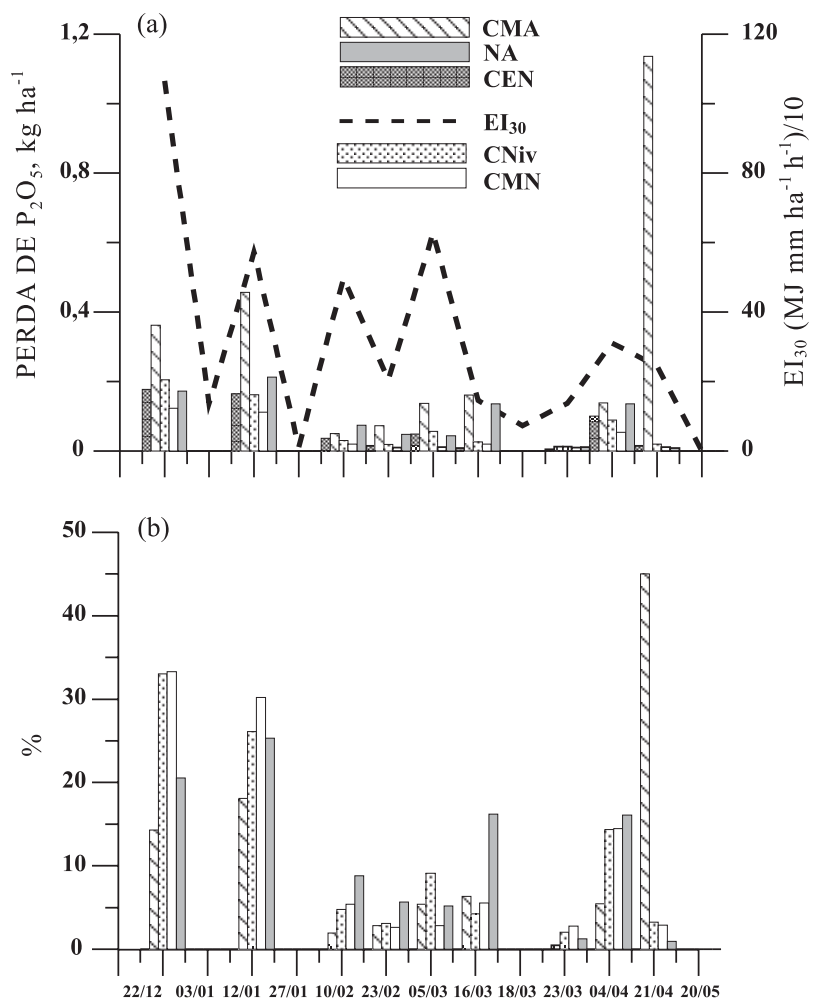

COLETA

Figura 4. Índice de erosividade de chuva $\left(\mathrm{EI}_{30}\right)$ e perdas de fósforo (a); percentuais das perdas em cada coleta (b); no período de dezembro de 2005 a junho de 2006 em diferentes preparos de solo na Fazenda Mourão I. CMA: convencional morro abaixo; NA: duas gradagens niveladoras; CEN: convencional em nível; CNiv: convencional com uma gradagem niveladora; $\mathrm{CMN}$ : cultivo mínimo em nível. 

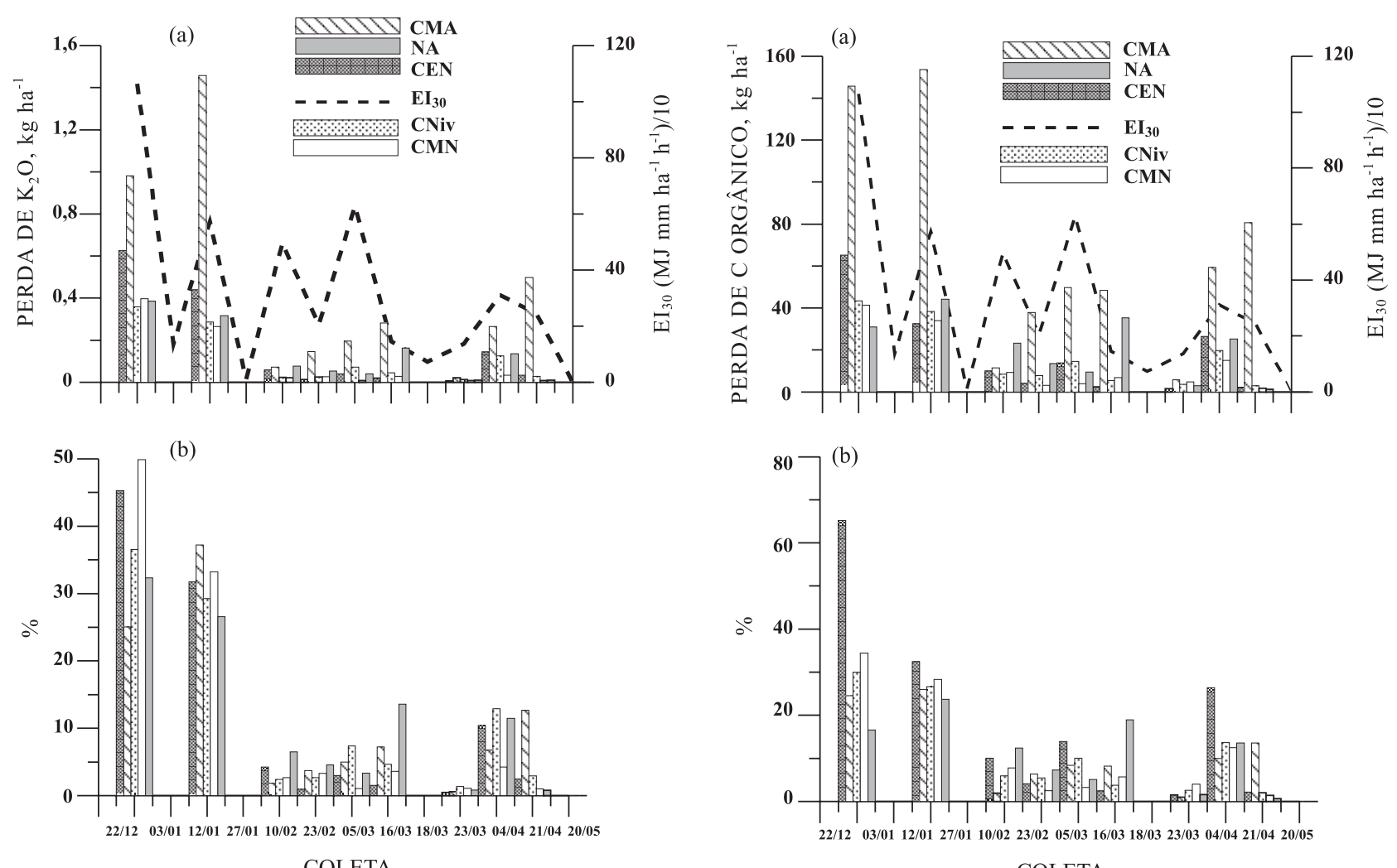

COLETA

Figura 5. Índice de erosividade de chuva $\left(\mathrm{EI}_{30}\right)$ e perdas de potássio (a), percentuais das perdas em cada coleta (b); no período de dezembro de 2005 a junho de 2006 em diferentes preparos de solo na Fazenda Mourão I. CMA: convencional morro abaixo; NA: duas gradagens niveladoras; CEN: convencional em nível; CNiv: convencional com uma gradagem niveladora; $\mathrm{CMN}$ : cultivo mínimo em nível.

motivos já descritos, até a terceira coleta ocorreram mais de 54 e $44 \%$ das perdas de nutrientes e C-org, respectivamente, nos tratamentos CNiv e NA.

Em relação ao C-org (Figura 6a), foram observadas maiores perdas do elemento no preparo NA em comparação ao CNiv, devido à incorporação parcial dos resíduos vegetais no solo pelos respectivos preparos, como já discutido anteriormente de forma análoga às perdas de $\mathrm{N}$, concordando com Guadagnin et al. (2005).

Com relação aos tipos de preparo do solo, pode-se observar (Figura 7) que as perdas totais de solo, N, P, $\mathrm{K}$ e C-org em sedimento no tratamento CMA foram estatisticamente maiores às dos demais tratamentos. Apesar de não ter sido observada diferença significativa entre os tratamentos CEN, CNiv, CMN e NA, pode-se constatar que, de maneira geral, as parcelas em que o solo foi submetido à maior revolvimento tenderam a apresentar maiores perdas dos atributos e sedimento, sendo observadas as menores perdas no tratamento CMN.

Figura 6. Índice de erosividade de chuva $\left(\mathrm{EI}_{30}\right)$ e perdas de carbono orgânico (a), percentuais das perdas em cada coleta (b); no período de dezembro de 2005 a junho de 2006 em diferentes preparos de solo na Fazenda Mourão I. CMA: convencional morro abaixo; NA: duas gradagens niveladoras; CEN: convencional em nível; CNiv: convencional com uma gradagem niveladora; CMN: cultivo mínimo em nível.

Pode-se observar que as perdas de solo no tratamento CEN foram mais baixas que as apresentadas no tratamento CMA (Figura 7). Observa-se que o preparo e a semeadura em nível reduziram as perdas de solo em $75 \%$, quando comparados ao preparo do CMA. Esta redução devese ao fato do preparo em nível propiciar uma redução na velocidade e tensão cisalhante do escoamento superficial, reduzindo sua capacidade de transporte e de desprendimento das partículas de solo. Segundo Bertoni \& Lombardi Neto (1990), o cultivo em nível pode reduzir em até $50 \%$ as perdas de solo em relação ao cultivo morro abaixo.

Quanto às perdas de nutrientes e C-org do tratamento CEN (Figura 7) ao longo das coletas, foram muito semelhantes às da perda de solo, sendo a prática do cultivo e o preparo em nível (CEN) responsáveis por reduzir as perdas em 78, 65, 77 e $73 \%$ para $\mathrm{N}, \mathrm{K}, \mathrm{P}$ e C-org, respectivamente, em comparação ao preparo CMA.

Na figura 8 apresenta-se a relação da perda de solo e produtividade da cultura do algodoeiro nos diferentes 
sistemas de preparo de solo. Pode-se observar que, para produzir um quilo de algodão, perderam-se $7 \mathrm{~kg}$ de solo no preparo de CMA, condição esta mais crítica de preparo de solo. Segundo Bertolini et al. (1993), são perdidos em torno de $12 \mathrm{~kg}$ de solo para cada quilo de algodão produzido no Estado de São Paulo, devido ao uso e manejo. Nos preparos CNiv, NA, CEN e CMN, foram perdidos, respectivamente, 2,$4 ; 2,2 ; 2,1$; e 1,7 kg de solo para produzir $1 \mathrm{~kg}$ de algodão.

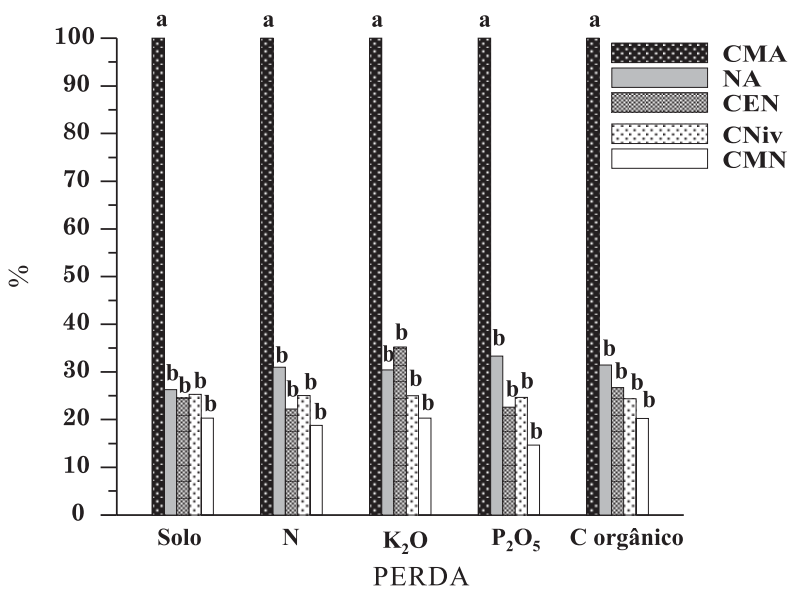

Figura 7. Perdas totais relativas ao preparo convencional morro abaixo (CMA) para as perdas de solo, nitrogênio $(\mathrm{N})$, potássio $\left(\mathrm{K}_{2} \mathrm{O}\right)$, fósforo $\left(\mathrm{P}_{2} \mathrm{O}_{5}\right)$ e carbono orgânico (C-org) em sedimento.

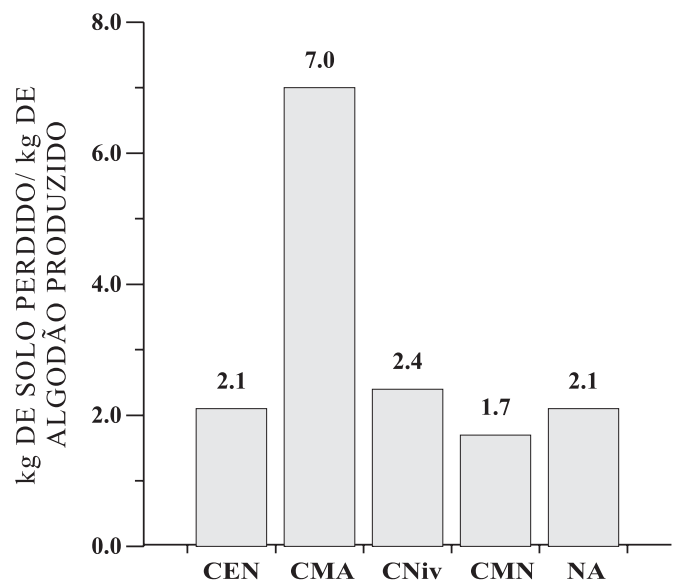

Figura 8. Relação da perda de solo e produtividade da cultura do algodoeiro em diferentes sistemas de preparo de solo.

\section{CONCLUSÕES}

1. As perdas de solo foram mais elevadas durante o estabelecimento da cultura, período mais crítico tendo em vista a maior erosividade das chuvas e a menor cobertura do solo.
2. Os preparos que proporcionaram menor revolvimento do solo apresentaram menores perdas de solo, nutrientes e C orgânico, destacando o CMN como o mais eficiente.

3. O C orgânico foi o constituinte encontrado em maior quantidade no sedimento erodido.

4. A taxa de infiltração básica (TIB) expressou diferença, entre os tratamentos, na seguinte ordem em valores crescentes $\mathrm{CMA}<\mathrm{CEN} \cong \mathrm{CNiv} \cong \mathrm{NA}<\mathrm{CMN}$.

\section{LITERATURA CITADA}

AMADO, T.J.C.; COGO, N.P. \& LEVIEN, R. Eficácia relativa do manejo de resíduo cultural de soja na redução das perdas de solo por erosão hídrica. R. Bras. Ci. Solo, 13:151157,1989

BERTOL, I.; SCHICK, J.; MASSARIOL, J.M.; REIS, E.F. \& DILLY, L. Propriedades físicas de um Cambissolo Húmico álico afetadas pelo manejo do solo. Ci. Rural, 30:91-95, 2000.

BERTOL, I.; COGO, N.P.; SCHICK, J.; GUDAGNIN, J.C.E. \& AMARAL, A.J. Aspectos financeiros relacionados às perdas de nutrientes por erosão hídrica em diferentes sistemas de manejo do solo. R. Bras. Ci. Solo, 31:133-142, 2007.

BERTOL, I.; ALBUQUERQUE, J.A.; LEITE, D.; AMARAL, A.J. \& ZOLDAN JUNIOR, W.A. Propriedades físicas do solo sob preparo convencional e semeadura direta em rotação e sucessão de culturas, comparadas às do campo nativo. R. Bras. Ci. Solo, 28:155-163, 2004.

BERTOL, I.; COGO, N.P. \& LEVIEN, R. Erosão hídrica em diferentes preparos do solo logo após as colheitas de milho e trigo, na presença e ausência de resíduos culturais. $R$. Bras. Ci. Solo, 21:409-418, 1997.

BERTOLINI, D.; LOMBARDI NETO, F. \& DRUGOWICH, M.I. Programa Estadual de Bacias Hidrográficas. Campinas, Secretaria da Agricultura e Abastecimento do Estado de São Paulo, CATI, 1993. 17p. (Impresso Especial)

BERTONI, J. \& LOMBARDI NETO, F. Conservação do solo. Piracicaba, Livroceres, 1990. 392p.

CARVAlHO, F.L.C.; COGO, N.P. \& LEVIEN, R. Eficácia relativa de doses e formas de manejo do resíduo cultural de trigo na redução da erosão hídrica do solo. R. Bras. Ci. Solo, 13:251-257, 1990.

CASTRO FILHO, C.; MUZILLI, O. \& PODANOSCHI, A.L. Estabilidade dos agregados e sua relação com o teor de C orgânico em um Latossolo Roxo distrófico, em função de sistemas de plantio, rotações de culturas e métodos de preparo das amostras. R. Bras. Ci. Solo, 22:527-538, 1998.

COGO, N.P.; MOLDENHAUER, W.C. \& FOSTER, G.R. Soil loss reductions from conservation tillage practices. Soil Sci. Soc. Am. J., 48:368-373, 1984. 
DEDECEK, R.A.; RESK, D.V.S. \& FREITAS, J.E. Perdas de solo, água e nutrientes por erosão em Latossolo VermelhoEscuro dos Cerrados em diferentes cultivos sob chuva natural. R. Bras. Ci. Solo, 10:265-272, 1986.

ELTZ, F.L.F.; PEIXOTO, R.T.G. \& JASPER, F. Efeitos de sistemas de preparo do solo nas propriedades físicas e químicas de um Latossolo Bruno álico. R. Bras. Ci. Solo, 13:259-267, 1989.

ELTZ, F.L.F.; COGO, N.P. \& MIELNICZUK, J. Perdas por erosão em diferentes manejos de solo e coberturas vegetais em solo Laterítico Bruno Avermelhado distrófico (São Jerônimo). I. Resultados do primeiro ano. R. Bras. Ci. Solo, 1:123-127, 1977.

EMPRESA BRASILEIRA DE PESQUISA AGROPECUÁRIA EMBRAPA. Serviço Nacional de Levantamento e Conservação do Solo. Manual de análises de solo. 2.ed. Rio de Janeiro, 1997. 212p.

EMPRESA BRASILEIRA DE PESQUISA AGROPECUÁRIA EMBRAPA. Sistema brasileiro de classificação de solos. 2.ed. Rio de Janeiro, Embrapa Solos, 2006. 306p.

GUADAGNIN, J.C.; BERTOL, I.; CASSOL, P.C. \& AMARAL, A.J. Perdas de solo, água e nitrogênio por erosão hídrica em diferentes sistemas de manejo. R. Bras. Ci. Solo, 29:277-286, 2005.

HERNANI, L.C.; FREITAS, P.L.; PRUSKI, F.F.; De MARIA, I.C.; CASTRO FILHO, C. \& LANDERS, J.C. A erosão e seu impacto. In: MANZATTO, C.V.; FREITAS JÚNIOR, E. \& PERES, J.R.R., eds. Uso agrícola dos solos brasileiros. Rio de Janeiro, Embrapa, 2002. p.47-60.

JACKSON, M.L. Soil chemical analysis. Englewood Cliffs, Prentice-Hall, 1958. 498p.

LIMA, C.L.R.; PAULETTO, E.A.; GOMES, A.S. \& SILVA, J.B. Estabilidade de agregados de um Planossolo sob diferentes sistemas de manejo. R. Bras. Ci. Solo, 27:199-205, 2003.

LOPES, P.R.C.; COGO, N.P. \& LEVIEN, R. Eficácia relativa de tipo e quantidade de resíduos culturais espalhados uniformemente sobre o solo na redução da erosão hídrica. R. Bras. Ci. Solo, 11:71-75, 1987.

MORAIS, L.F.B.; SILVA, V.; NASCHENVENG, T.M.C.; HARDOIN, P.C.; ALMEIDA, J.E.L.; WEBER, O.L.S.; BOEL, E. \& DURIGON, V. Índice $\mathrm{EI}_{30}$ e sua relação com o coeficiente de chuva do sudoeste de Mato Grosso. R. Bras. Ci. Solo, 15:339-344, 1991.
NUNES FILHO, J.; SOUSA, A.R.; MAFRA, R.C. \& JACQUES, F.O. Efeito do preparo do solo sobre as perdas por erosão e produção de milho num Podzólico Vermelho-Amarelo eutrófico de Serra Talhada (PE). R. Bras. Ci. Solo, 11:183$186,1987$.

PARANÁ. Secretaria de estado da agricultura e do abastecimento. Manual técnico do subprograma de manejo e conservação do solo. Curitiba, 1989. 306p.

PEREIRA, S.B. Despreendimento e arraste de solo em decorrência do escoamento superficial. Viçosa, MG, Universidade Federal de Viçosa, 1999. 81p. (Tese de Mestrado)

PRUSKI, F.F.; SILVA, D.D.; SANTOS, W.L.; RODRIGUES, L.N. \& ANTTUNES, V.L. Infiltração de água no solo. LOCAL, EDITORA, 1997. 26p. (Caderno didático, 25).

SLONEKER, L.L. \& MOLDENHAUER, W.C. Measuring the amounts of crop residue remaining after tillage. J. Soil Water Cons., 32:231-236, 1977.

SCHICK, J.; BERTOL, I.; BATISTELA, O. \& BALBINOT Jr., A.A. Erosão hídrica em Cambissolo Húmico alumínico submetido a diferentes sistemas de preparo e cultivo do solo: I. Perdas de solo e água. R. Bras. Ci. Solo, 24:427436, 2000 .

SEGANFREDO, M.L.; ELTZ, F.L.F. \& BRUM, A.C.R. Perdas de solo, água e nutrientes por erosão em sistemas de culturas em plantio direto. R. Bras. Ci. Solo, 21:287-291, 1997.

SILVA, D.D.; PRUSKI, F.F.; SCHAEFER, C.E.G.R.; AMORIM, R.S.S. \& PAIVA, K.W.N. Efeito da cobertura nas perdas de solo em um Argissolo Vermelho-Amarelo utilizando simulador de chuva. Eng. Agríc., 25:409-419, 2005.

TAPIA-VARGAS, M.; TISCAREÑO-LÓPEZ, M.; STONE, J.J.; OROPEZA-MOTA, J.L. \& VELAÂZQUEZ-VALLE, M. Tillage system effects on runoff and sediment yield in hillslope agriculture. Field Crops Res., 69:173-182, 2001.

VIEIRA, M.J.; COGO, N.P. \& CASSOL, E.A. Perdas por erosão nos diferentes sistemas de preparo do solo para a cultura da soja (Glycine Max), em condições de chuva simulada. R. Bras. Ci. Solo, 2:209-214, 1978.

WISCHMEIER, W.H. \& SMITH, D.D. Predicting rainfall erosion losses: A guide to conservation planning. Washington, USDA, 1978. 58p. (Agricultural Handbook, 537) 
